\title{
A questão habitacional em projetos de urbanização de baixadas em Belém/PA: dois estudos de caso'
}

\section{The housing issue in urbanization of waterlogged areas in Belém/PA: two case studies}

\section{Leão, Monique'; Azevedo, Camila²; Nascimento, Vitória ${ }^{3}$; Moraes, Trycia)4; Oliveira, Sâmya ${ }^{5}$}

\author{
1 Faculdade Estácio Belém, Av. José Malcher, 1148, Belém/PA, Brasil, \\ monique.bentes@gmail.com \\ 2 Universidade Federal do Pará, leticiazzevedo@gmail.com \\ 3 Faculdade Estácio Belém, vitoriaqueiroz21@hotmail.com \\ ${ }^{4}$ Faculdade Estácio Belém, trycia_isabele@hotmail.com \\ ${ }^{5}$ Faculdade Estácio Belém, samya.arquitetura@gmail.com
}

\begin{abstract}
RESUMO
O difícil acesso à terra urbanizada em Belém fez com que populações de baixa renda se assentassem em áreas de várzea, popularmente conhecidas como baixadas. 0 adensamento populacional e os impactos de uma infraestrutura incompleta, em conjunto com pobreza e precariedade habitacional tem levado essas áreas a receberem grandes intervenções de macrodrenagem e urbanização, o que gera alto número de remoções. $O$ objetivo da pesquisa é analisar a produção habitacional a partir de duas experiências de urbanização de baixadas em Belém: o Residencial Liberdade e o Residencial Portal da Amazônia. Ambos elaborados no âmbito do Programa de Aceleração do Crescimento (PAC) iniciados a partir de 2007 na cidade. Discute-se o processo de reassentamento de famílias, com paralisações de obras, e por conseguinte indefinição na entrega das unidades habitacionais pelas famílias atingidas. E questiona-se os projetos habitacionais estandardizados que não dialogam com o modo de vida amazônico e que podem significar rupturas e dificuldades de adequação à moradia.
\end{abstract}

Palavras-chave: Urbanização de assentamentos precários, Baixadas, Habitação de Interesse Social.

\section{ABSTRACT}

The difficult access to urbanized land in Belém meant that low-income populations settled in waterlogged areas, popularly known as "baixadas". The population density and the impacts of an incomplete infrastructure, coupled with poverty and housing precariousness have led these areas to receive large interventions of macrodrainage and urbanization, which generates a high number of removals. The objective of the research is to analyze the housing

1 LEÃO, Monique; AZEVEDO, Camila; NASCIMENTO, Vitória; MORAES, Trycia; OLIVEIRA, Sâmya. A Questão habitacional em projetos de urbanização de baixadas em Belém/ PA: dois estudos de caso. In: II SIMPÓSIO NACIONAL DE GESTÃO E ENGENHARIA URBANA: SINGEURB, 2019, São Paulo. Anais... Porto Alegre: ANTAC, 2019. 
production from two experiences of urbanization of Baixadas in Belém: the Residencial Liberdade and the Residencial Portal da Amazônia. Both developed under the Growth Acceleration Program (PAC) started in 2007 in the city. The process of resettlement of families is discussed, where there are work stoppages, and consequently the lack of definition in the delivery of the housing units by the affected families. And it questions the standardized housing projects that do not dialogue with the Amazonian way of life and that can mean ruptures and difficulties of adequacy to the dwelling.

Keywords: Urbanization of precarious settlements, waterlogged areas, Housing of Social Interest.

\section{INTRODUÇÃO: A PROBLEMÁTICA HABITACIONAL EM BELÉM}

Belém é uma cidade que historicamente possui problemas urbanísticos relacionados a sua característica geográfica, vistas como obstáculo para a expansão urbana, sendo necessária uma constante "luta" contra as áreas alagadas (MOREIRA 1966). Os terrenos nas áreas de várzea, constituíram-se opção mais acessível à população de baixa renda para construir suas moradias, por meio de construções adaptadas à várzea amazônica como palafita e a estiva (figura 1), enquanto as terras mais altas foram sendo comercializadas e ocupadas pela população de maior poder aquisitivo e por instituições públicas. Essas áreas formadas por planícies de inundação e terras alagáveis foram designadas de "baixadas" pelo setor público, correspondendo a cerca de $40 \%$ da área urbana de Belém (PINHEIRO et al 2007).

Figura 1 - Baixada de Belém/PA

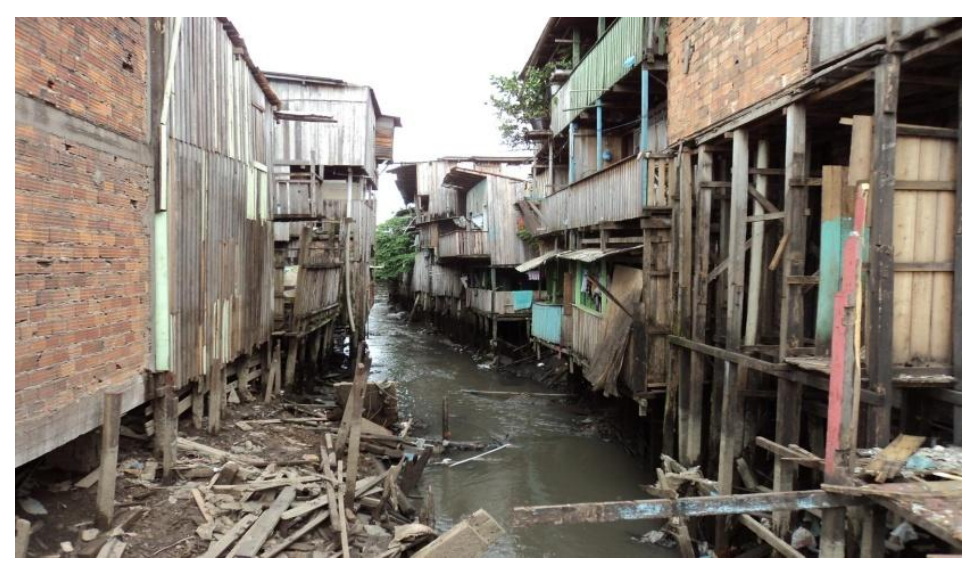

Foto: Juliano Ximenes, 2012.

A precariedade habitacional e insalubridade das baixadas fez com que se destacasse ações do setor habitacional relacionadas a projetos de saneamento (PINHEIRO et al 2007). Observase que até meados da década de 1980 a produção habitacional de interesse social, concentrada na COHAB/PA, construiu conjuntos habitacionais que seguiam o modelo BNH, com localizações periféricas, em áreas muitas vezes com características rurais e habitações com baixa qualidade, levando a série de impactos a famílias atingidas por deslocamentos. Após a década de 1990, a adoção da urbanização de favelas como padrão de intervenção, colaborou para programas de regularização fundiária e que incentivaram reassentamentos na área de intervenção, buscando diminuir impactos às famílias, e garantir o direito à localização (LEÃO, 2013).

A urbanização de favelas, quando incorporada ao PAC pelo governo federal (PAC-UAP), ganha uma nova escala, com recursos do orçamento da união (MARICATO, 2011). A proposta do PAC-UAP era viabilizar projetos com ações integradas em habitação, saneamento e inclusão social (BRASIL, 2010). Desta forma, representando uma ação estratégica e oportuna para intervenções em baixadas de Belém, que contou com 15 contratos (figura 2). Muitos destes projetos correspondem a assentamentos caracterizados por ocupações antigas e consolidadas, inseridas na malha urbana da cidade e com localizações centrais, vantajosas em relação ao acesso de serviços urbanos. Mas que aumentam o nível de complexidade das 
intervenções pela alta densidade populacional, necessidade de remoções para obras de infraestrutura, entre outros.

Figura 2- PAC-UAP em Belém/PA
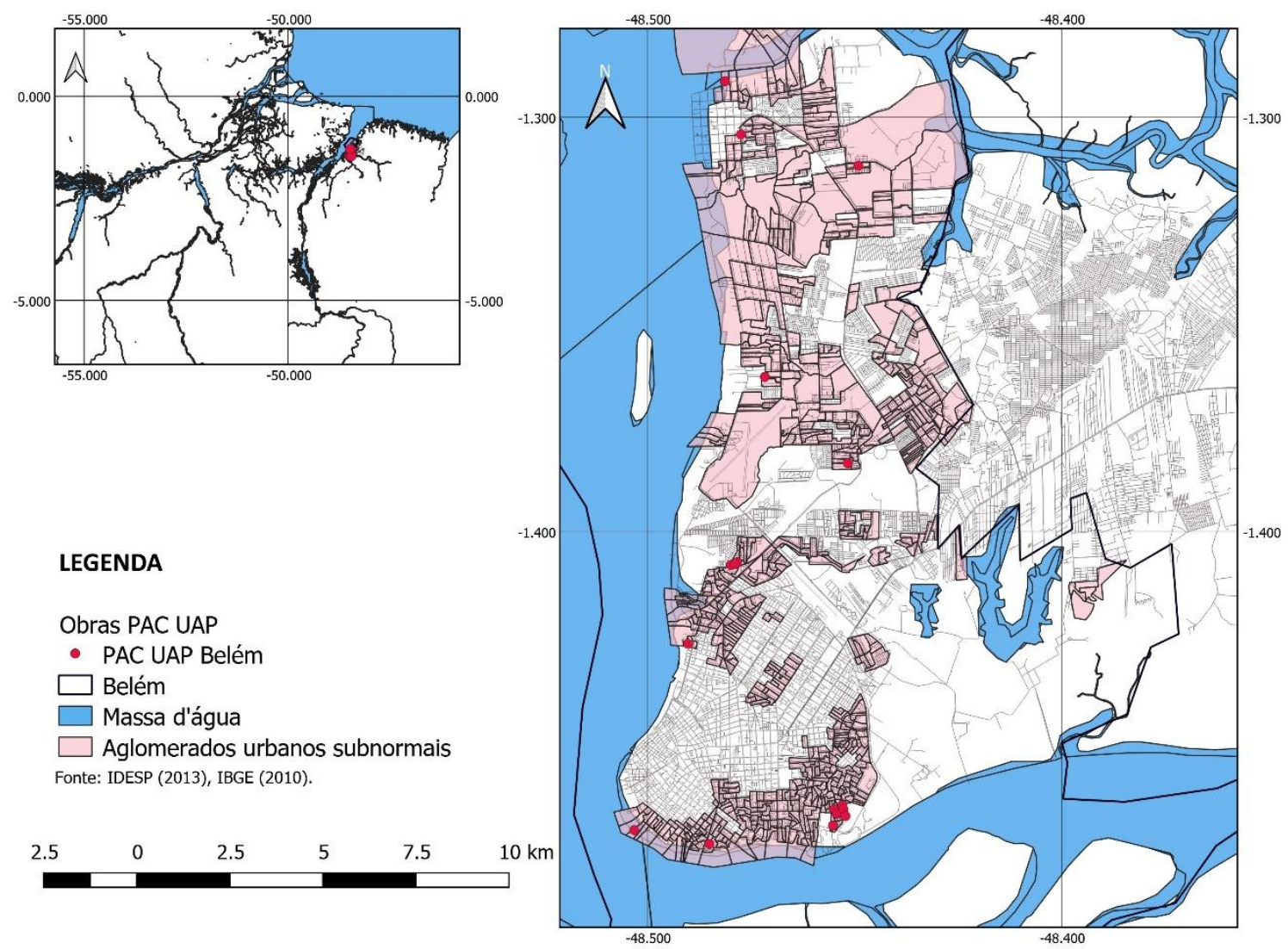

Fonte: IDESP-PA (2013), IBGE (2010).

Apesar dos avanços do PAC-UAP em incentivar as urbanizações em favelas, projetos de habitação ainda enfrentam problemáticas (CARDOSO; DENALDI, 2018). Em Belém, observase projetos que não priorizaram o morador, mas sim o barateamento da construção, prejudicando a qualidade da moradia. Muitas vezes, não são feitos estudos relacionados a sua implantação, ou mesmo analisado a melhor tipologia habitacional para a região, sendo normalmente implantado um "modelo genérico". Ou seja, a mesma tipologia utilizada para diversas regiões do país com características climáticas e topográficas diferentes.

O objetivo da pesquisa é analisar a produção habitacional no contexto de urbanização de assentamentos precários em Belém, sendo utilizado dois estudos de casos: Residencial Liberdade e Residencial Portal da Amazônia. Metodologicamente utiliza-se os parâmetros de qualidade para projetos habitacionais proposto por Ferreira (2012) que propõem uma análise, por meio de três escalas: Inserção Urbana, Implantação e Unidades Habitacionais. Para o autor, a inserção urbana está relacionada ao direito a urbanização, da moradia inserida no meio urbano facilitando o acesso à cidade, com infraestrutura, equipamentos urbanos $e$ acesso ao emprego mais fácil. A implantação trata da forma como a habitação é inserida no terreno, em termos topográficos, paisagísticos, como ela interage com o entorno e com o meio ambiente. E a unidade habitacional trata de estratégias de conforto ambiental, soluções construtivas, distribuição de ambientes internos, seu dimensionamento e flexibilidade para com as diferentes necessidades e composições familiares dos moradores, entre outros (FERREIRA, 2012). 


\subsection{Estudo de caso: Residencial Liberdade}

O adensamento populacional na região da bacia do Tucunduba se dá na década de 1980, sua área alagada e considerada periférica foi a alternativa encontrada por famílias, principalmente oriundas do interior do estado. Em 1990, foi proposta a primeira intervenção para a urbanização da bacia do Tucunduba, com uma proposta que destacava-se pela valorização dos córregos e soluções de reassentamento que respeitavam o modo de viver da comunidade, com a utilização de portos e praças para o uso da população (PMB, 2000 apud BARBOSA, 2003), a primeira etapa da obra começou a ser executada em 1997, com várias mudanças de propostas e interrupções ao longo do caminho. Em 2008, iniciou-se o projeto da $2^{a}$ e $3^{a}$ etapa de macrodrenagem do lgarapé Tucunduba, em conjunto, foi proposto 0 reassentamento da população atingida para o Residencial Liberdade, projeto elaborado pelos escritórios Cooperativa e Meia Dois Nove, em conjunto com a COHAB-PA. O projeto do Residencial Liberdade foi pensado para duas áreas: Liberdade 1 e 2, ambos com o mesmo conceito e partido. O terreno dos conjuntos está situado nas margens do igarapé Tucunduba, e pertencia a Universidade Federal Do Pará, vizinha da área de intervenção, oferecendo uma localização com menor impacto as famílias e uma boa inserção urbana (figura 3). São previstos para o Residencial Liberdade 1 a produção de 276 unidades habitacionais para atender 1.360 habitantes, e o Residencial Liberdade 2 seria composto por 2.028 unidades para atender 10.140 habitantes (MEIA DOIS NOVE, 2008).

Figura 3 - Inserção urbana do Residencial Liberdade I e II

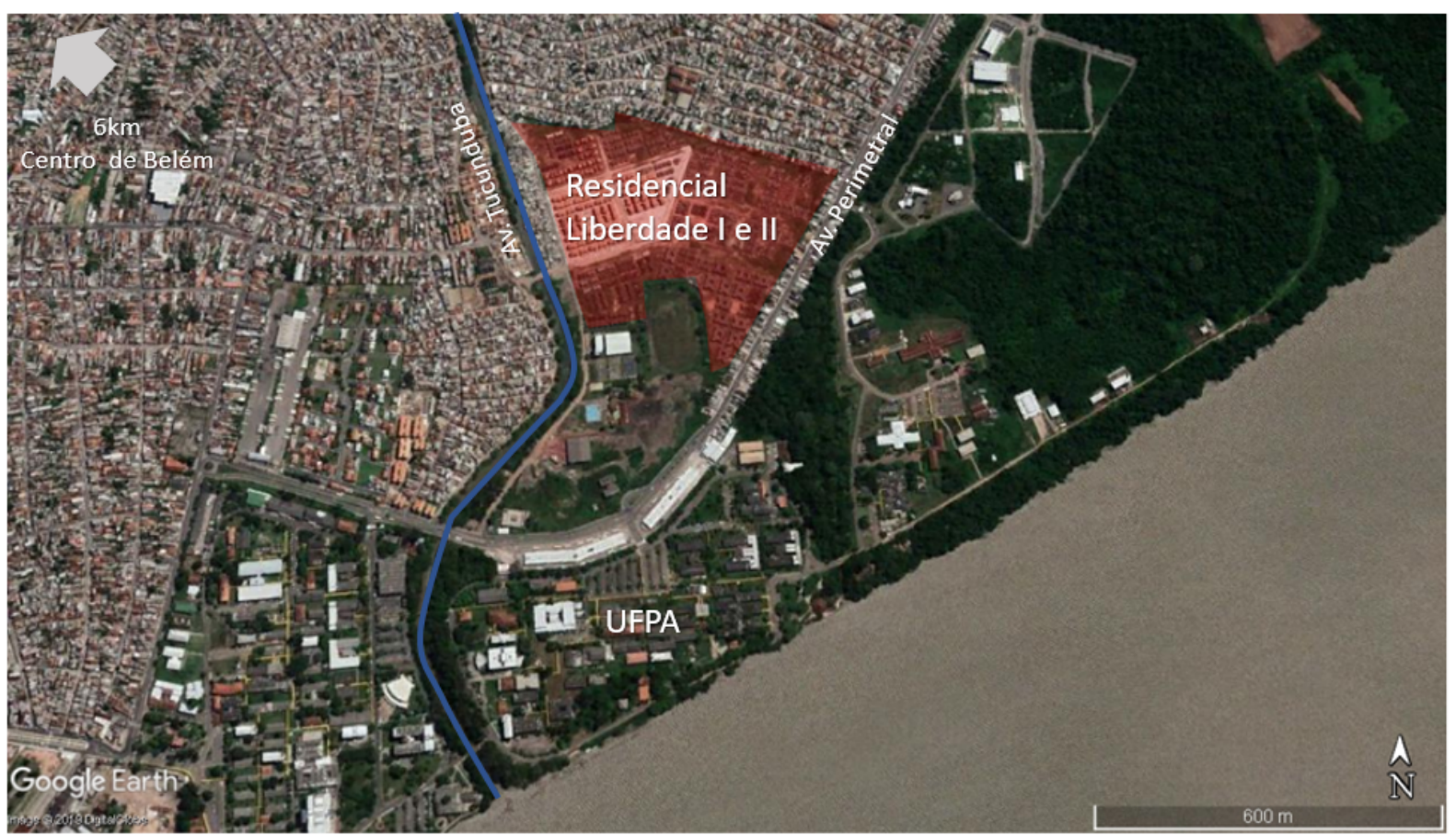

Fonte: Google Earth, 2018 (editado pelos autores).

O projeto destaca-se por não adotar as tipologias padrões da COHAB/PA, buscando variedade tipológica e adoção da tecnologia construtiva em cerâmica armada (sistema construtivo "terra \& teto" criada pela Cooperativa), que oferece baixo custo e racionalização da construção. Segundo o memorial do projeto, foi realizado um levantamento com os moradores, permitindo a participação dos mesmos para a concepção projetual, além de não se restringir somente a habitação e ter uma preocupação maior com o modo de viver dos futuros moradores do conjunto, visto que o complexo apresenta unidades de uso misto (habitação e comércio para as famílias cadastradas que sobreviviam de atividade comercial), além de um mercado e um CRAS (centro de referência e assistência social). A 
implantação das edificações foi pensada através da criação de pequenas praças e variedades de sobrados, que teria o objetivo de atender às demandas subjetivas dos moradores (MEIA DOIS NOVE, 2008). Desta forma, considera-se positiva a variedade tipológica, implantação e inserção urbana do conjunto (figura 4).

Figura 4 - Quadro síntese do projeto

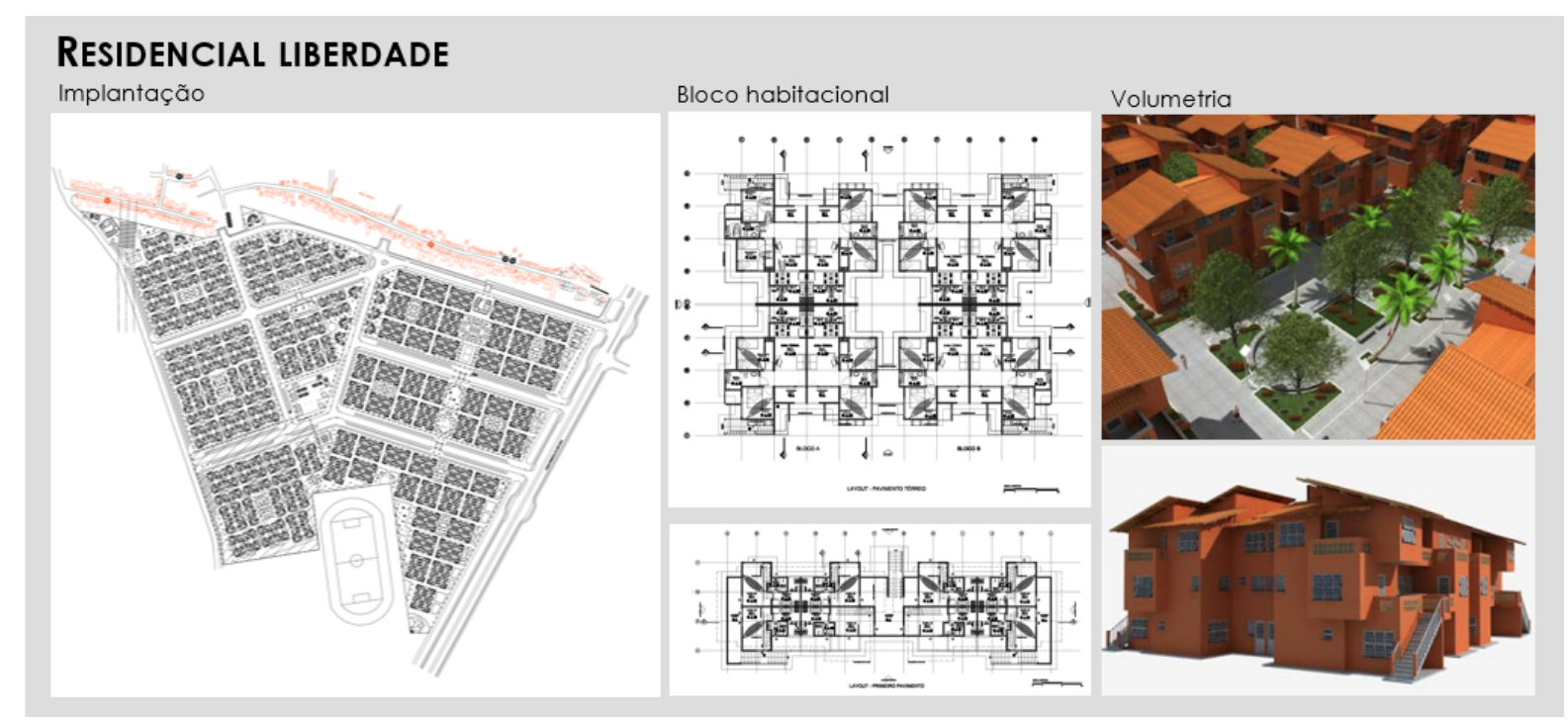

Fonte: COHAB/PA (2008), MEIA DOIS NOVE (2008).

No entanto, a estética das edificações foge do contexto local, o partido baseado no modo de viver típico das favelas não se enquadra nas referências da população amazônica, e as necessidades atendidas ainda não se enquadram totalmente dentro da forma de morar regional. Outro fator de limitação é a gestão das obras, após 10 anos de execução, ainda se encontra incompleta, com paralisações ocorridas por troca de gestores, ocupações aos blocos inacabados e necessidade de remoções, o que prolonga ainda mais a entrega para as famílias, aumentando os transtornos causados pelo reassentamento, incluindo descrença do recebimento da moradia.

\subsection{Estudo de caso: Residencial Portal da Amazônia}

O projeto Portal da Amazônia faz parte de um projeto maior de macrodrenagem da Bacia da Estrada Nova, é uma das propostas de reurbanização da orla de Belém, tal orla marcada por ocupações irregulares, reconhecida por apresentar maior número de famílias em precariedade segundo dados do IBGE (LEÃO, 2013). O projeto visa solucionar a questão dos alagamentos da região, implantar infraestrutura urbana, propor um espaço de lazer e integrar a área de intervenção a malha viária da cidade. Para dar espaço a esta intervenção, parte da população que ali vivia precisou ser realocada, algumas famílias "receberam a indenização pelo seu imóvel, e, pelo fato de o valor ser menor do que o desejado, não conseguiu adquirir outra moradia, perdendo toda a indenização." (BARBOSA et al., 2014). Outra parte da população seria reassentada no Residencial Portal da Amazônia, que, segundo Leão (2013), seria localizado no mesmo local da obra e contaria com 221 unidades, porém desde 2012 as obras estão paralisadas, com apenas 16 unidades entregues (figura 5). Durante a espera, as famílias recebiam um valor de auxílio moradia no valor de $\mathrm{R} \$ 500,00$ (BARBOSA et al., 2014). Contudo com este valor dificilmente as famílias encontravam moradias próximas a área, criando problemas no orçamento das famílias atingidas. 
Figura 5 - Inserção urbana do projeto Residencial Portal da Amazônia

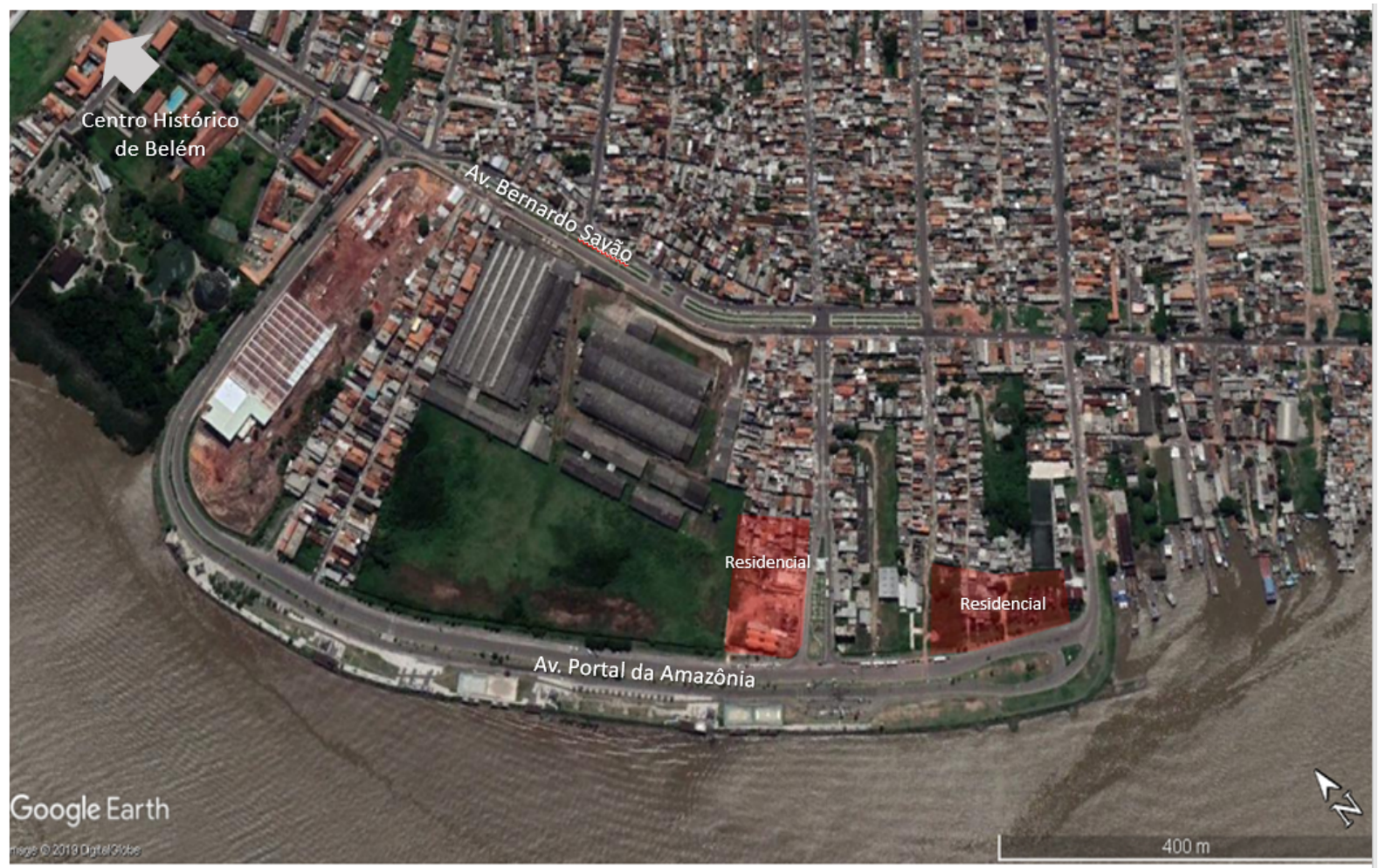

Fonte: Google Earth, 2018 (editado pelos autores).

O projeto habitacional apresenta baixa qualidade arquitetônica, com blocos em formato de ' $\mathrm{H}$ ', locadas de maneira 'carimbada' ao longo dos dois terrenos previstos para $\mathrm{O}$ reassentamento, não há variedade tipológica das unidades e sua dimensão pode ser considerada muito reduzida, com $42,83 \mathrm{~m}^{2}$. Na Implantação as áreas de lazer foram localizadas nas extremidades do residencial, com tendência a gerar cantos ociosos que não cooperam para o bom funcionamento do espaço urbano (figura 6).

Figura 6-Quadro síntese do projeto

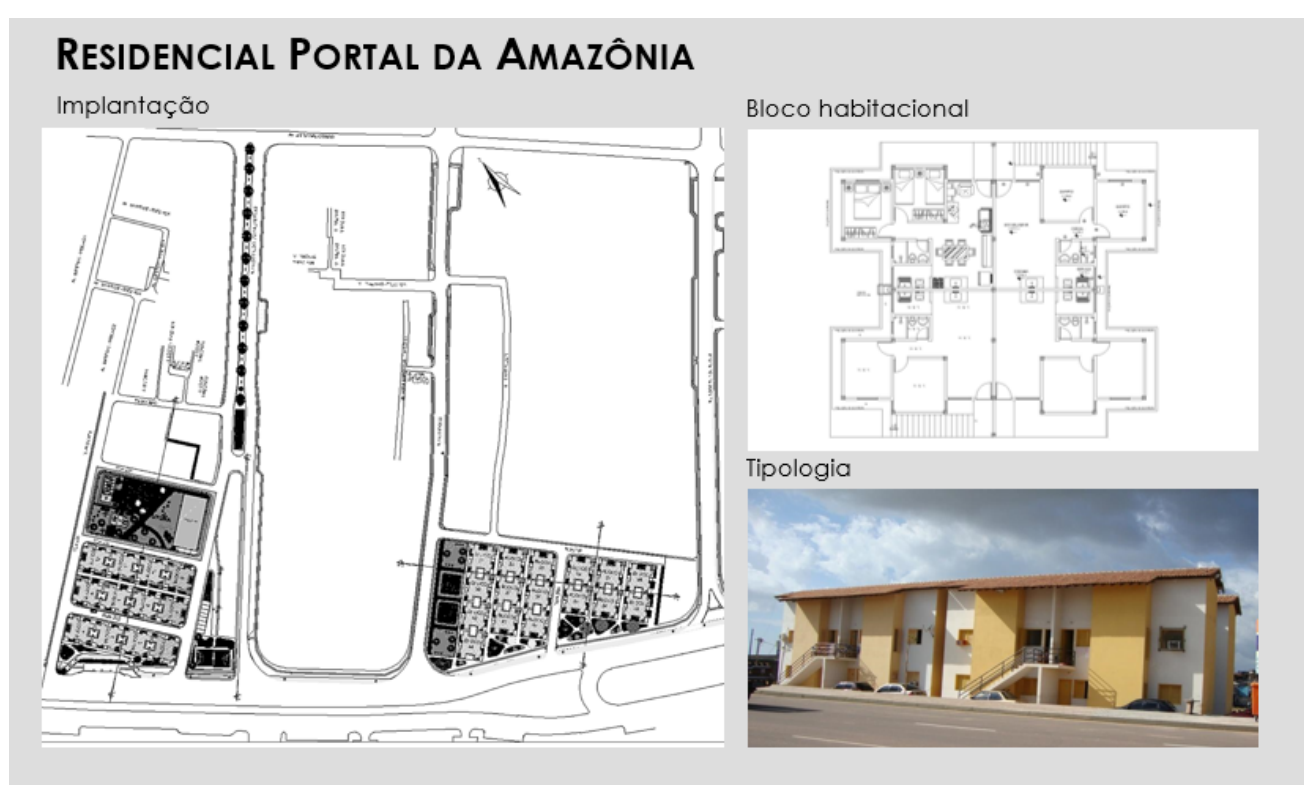

Fonte: Prefeitura de Belém (2008; 2012); Autores (2018). 
O cenário atual do Portal da Amazônia é um amplo espaço de lazer. Porém, o que se vê do outro lado do parque linear é uma grande área de urbanização incompleta, apresentando dois blocos habitacionais implantados abaixo do nível da rua, blocos inacabados e a presença de moradias palafíticas em situação de precariedade. Além de terrenos privados em especulação. A troca da gestão municipal, em 2013, fez com que os projetos habitacionais passassem por revisão, estando ainda inconclusos e com obras paralisadas em 2019. Após 2013, a solução apresentada para as famílias em espera foi a inserção no Programa Minha Casa Minha Vida gerido pela Prefeitura, com residenciais distantes a cerca de 15 a $20 \mathrm{~km}$ da área.

\section{CONCLUSÕES}

Apesar das propostas analisadas promoverem localizações vantajosas para o realocado, ocorre uma problemática na gestão do reassentamento, envolvendo desde problemas na execução do projeto, a qualidade projetual. O Residencial Liberdade busca na implantação o conceito de unidade de vizinhança, e promover variedade tipológica que atendessem as necessidades do morador, no entanto, o atraso na entrega da unidade habitacional é algo prejudicial para a população atingida.

O projeto Residencial do portal da Amazônia apresenta uma boa inserção urbana, no entanto sua implantação não possui maiores preocupações urbanísticas e paisagísticas. Em relação a solução habitacional, pode-se criticar a baixa qualidade e pouco avanço tecnológico. Em geral, são reproduzidos modelos padronizados pelo poder público, que visam a economia da execução e o atendimento máximo de famílias.

Entende-se que o deslocamento involuntário causado por projetos de infraestrutura e urbanização é um processo complexo e gerador de diversos impactos socioeconômicos às famílias atingidas. Neste sentido, observa-se uma dificuldade para o gerenciamento de projetos habitacionais em baixadas de Belém. Em ambos os projetos, nota-se dificuldades, com atrasos, execuções longas, gerando desgaste das famílias. Desta forma, demonstra-se a necessidade de maiores discussões a respeito da habitação de interesse social adequada a região, com estudos de tipologias e tecnologias adequadas.

\section{REFERÊNCIAS}

BARBOSA, André. E† al. Portal da Amazônia: Uma análise sobre o processo de ocupação e (des)ocupação. In: Anais do VII CBG, 2014, Vitória/ES. A AGB e a Geografia brasileira no contexto das lutas sociais frente aos projetos hegemônicos, 2014.

BARBOSA, Maria José de Souza. SÁ, Maria Elvira Rocha de. SOUZA, Armando Lírio de. Estudo de caso: Tucunduba: Urbanização do Igarapé Tucunduba, Gestão de Rios Urbanos Belém/Pará - versão condensada. Belém, UFPA, 2003.

BRASIL. Ministério das Cidades. Secretaria Nacional de Habitação. Urbanização de Favelas: a experiência do PAC. Brasília, 2010.

CARDOSO, Adauto Lúcio; DENALDI, Rosana. Balanço. In: Urbanização de Favelas no Brasil: um balanço preliminar do PAC. $1^{a}$ Ed. Rio de Janeiro: Letra Capital, 2018.

FERREIRA, João Sette Whitaker. Produzir casas ou construir cidades? Desafios para um novo Brasil urbano. Parâmetros de qualidade para a implementação de projetos habitacionais e urbanos. São Paulo: LABHAB; FUPAM, 2012.

LEÃO, Monique. Remoção e reassentamento em baixadas de Belém: Estudos de caso de planos de reassentamento (1980-2010). 2013. 151 f. Dissertação (Mestrado) - Curso de Arquitetura e Urbanismo, Programa de Pós-graduação em Arquitetura e Urbanismo, Universidade Federal do Pará, Belém, 2013. 
MEIA DOIS NOVE. Conjunto Residencial Comunidade Liberdade I e II, Belém - Pará (2008). Memoriais da MeiaDoisNove. Abril, 2010. Disponível em:

<http://memoriaisdameiadoisnove.blogspot.com/2010/04/conjunto-residencialcomunidade.html> Acesso em 10 de janeiro de 2019.

MARICATO, Ermínia. O impasse da política urbana no Brasil. $1^{a}$ ed. Petrópolis-RJ: Vozes, 2011.

MOREIRA, E. Belém e sua expressão geográfica. In: MOREIRA, E. Obras reunidas de Eidorfe Moreira. Belém, 1989.

PINHEIRO Andréa; LIMA, José Júlio; SÁ, Maria Elvira, PARACAMPO, Maria Vitória e CARNEIRO, Moema. Experiências de promoção de habitação de interesse social na Região

Metropolitana de Belém: estudos de caso Conjunto Paraíso dos Pássaros e Vila da Barca. In: CARDOSO, Adauto Lúcio (org.). Habitação social nas metrópoles brasileiras: uma avaliação das políticas habitacionais em Belém, Belo Horizonte, Porto Alegre, Recife, Rio de Janeiro e São Paulo no final do século XX. Porto Alegre: ANTAC, 2007. (Coleção Habitare). 